\title{
High Speed Selective Gold Plating of Lead Frames
}

\section{A NEW SPRAY DEPOSITION PROCESS}

Selective plating was for some time considered an expensive method of electrodepositing gold, particularly when the capital investment in equipment would not be recovered over a period of several years. The techniques employed also tended to be somewhat primitive compared with today's systems, at least until the rise in the price of gold made a closer consideration of this type of process a more immediate requirement.

One particular component for which selective plating is ideally suited is the lead frame, so widely used in the electronics industry, on which gold is required only on the centre spot and on the edges of the circuit. A process, known as E.S.P. 400, developed by Engelhard Industries, Cinderford, Gloucestershire, England, now offers an economic and rapid method of depositing gold on to these areas only. This is achieved by the high speed spraying of a slightly acidic cyanide solution on to the area to be plated, the spray nozzle, made in platinum, serving as the anode.
By comparison with conventional gold plating, the current density employed is several times greater, and can be as high as $40 \mathrm{~A} / \mathrm{dm}^{2}$. The electrolyte, having a very low gold concentration of $6 \mathrm{~g} / \mathrm{l}$, is sprayed at a relatively high temperature, of the order of 50 to $60^{\circ} \mathrm{C}$, and is found to be quite stable and to be free from contamination by iron or nickel. It has been specially designed to withstand these high current densities and the more aggressive treatment encountered in this form of electrodeposition over a period of many months without the necessity of changing the solution.

The process yields a pure deposit with good bonding properties and, of course, complete resistance to tarnish. Solderability tests have also shown good results.

Lead frames can be gold plated either batch-wise or continuously in strip form in appropriate selective plating equipment, and the plating operation is usually complete within a few seconds.

D. R. M.

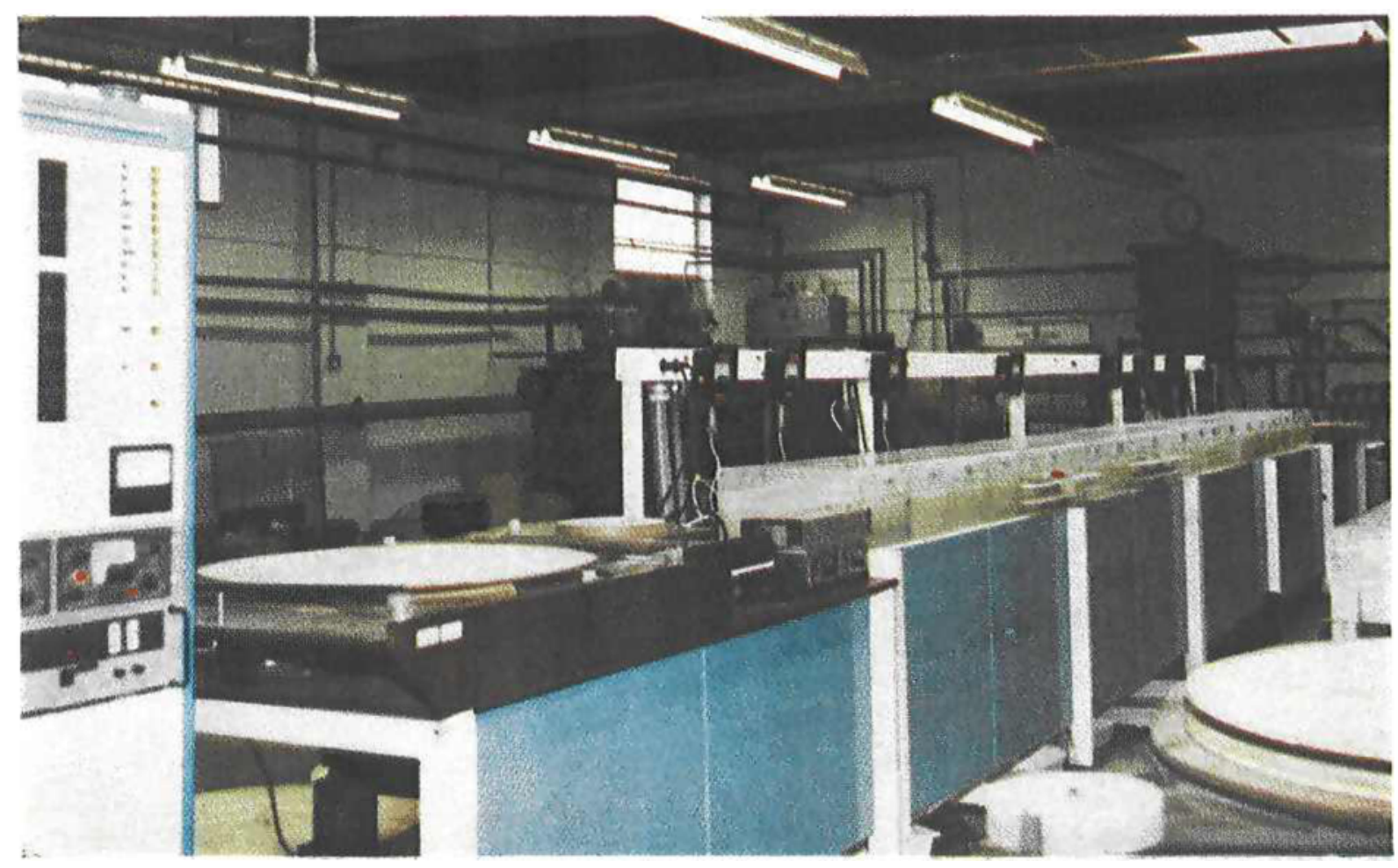

The Engelhard spray plating process is in use in this reel-to-reel continuous automatic equipment for the selective gold plating of lead frames at the Dynacraft-Morgan plant in Wellinghorough, Northamptonshire 